V5 and V6, and various forms of heart block. ${ }^{4}{ }^{7}$ At necropsy the heart is overweight and may reach as much as 730 g. ${ }^{8}$ The chambers are dilated, and thrombus is superimposed on thickened endocardium in about one-third of the hearts examined. Histologically, fibrous replacement of the myocardium is widespread, particularly in the subendocardial and the subepicardial regions. Fatty infiltration may sometimes be

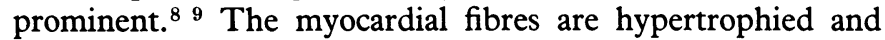
usually regularly arranged. If dilatation is severe the cell diameter may be normal, because of stretching. The coronary arteries are often widely patent, but may contain flecks of atheroma. The heart valves are usually unaffected, and the conducting tissue is often normal, ${ }^{8}$ though abnormal changes have been reported. ${ }^{30}$

More recently, attention has been drawn to the clinical manifestations of hypertrophic cardiomyopathy in patients with Friedreich's ataxia. ${ }^{31-14}$ The development of a cardiomyopathy has been confirmed by cardiac catheterisation and angiography ${ }^{11-13}$ and echocardiography, ${ }^{314}$ but so far not pathologically. In Canadian series of 11 patients ${ }^{3}$ two showed typical clinical evidence of hypertrophic cardiomyopathy while in two more there were characteristic echocardiographic changes. The ratio of septal to posterior wall thickness was increased, varying between 1.5 and 2.3 . That alone would not be diagnostic of hypertrophic cardiomyopathy (such changes have been described in congenital heart disease) and in fact histological changes suggestive of hypertrophic cardiomyopathy could be shown in only two of eight patients examined at necropsy. ${ }^{15}$ Furthermore, follow-up in many cases has shown that asymmetric septal thickening may resolve. ${ }^{16}$ Nevertheless, in the four Canadian patients in whom hypertrophic cardiomyopathy was diagnosed there was other suggestive evidence, including characteristic motion of the anterior leaflet of the mitral valve, decreased excursion and systolic thickening of the septum, and increased systolic thickening of the left ventricular free wall.

Numerous family studies have been undertaken in patients with Friedreich's ataxia,, 317 and inheritance is most commonly autosomal recessive ${ }^{18}$ or very occasionally sex linked. ${ }^{19}$ The two sexes are about equally affected. The high incidence of cardiac lesions has led to suggestions that the term Friedreich's ataxia should be replaced by Friedreich's disease. ${ }^{17}$ As yet, however, we cannot explain the mechanism of the association of cardiac abnormalities with the musculoskeletal lesions. Possibly a single common gene might be responsible, affecting skeletal and cardiac muscle. ${ }^{20} 21$ It seems unlikely that small vessel disease would be responsible for the myocardial changes, since pathological studies have shown that only $9 \%$ of vessels are narrowed sufficiently to have possibly caused fibrosis. Attempts to show abnormal tryptophan metabolism have yielded conflicting results. ${ }^{22}{ }^{23}$

The prognosis of patients with the syndrome is poor: $56 \%$ in one series died from heart failure ${ }^{8}$ and $17 \%$ had cardiac symptoms before death. It is, indeed, the cardiac disability that determines the ultimate outlook for these patients. In view of the evidence that hypertrophic obstructive cardiomyopathy may be associated with Friedreich's ataxia in a substantial number of cases, its early recognition may be of particular importance, since treatment may influence the prognosis favourably.

\footnotetext{
1 Friedreich, N, Virchows Archiv für pathologische Anatomiel und Physiologie, $1863,26,391$ and $433 ; 27,1$.

${ }^{2}$ Hartman, J M, and Booth, R W, American Heart fournal, 1960, 60, 716.

3 Smith, E R, et al, American Heart fournal, 1977, 94, 428.

4 Thorén, C, Acta Paediatrica, 1964, 53, suppl 153.

5 Schilero, A J, Antzis, E, and Dunn, J, American Heart fournal, 1952, 44, 805.
}

${ }^{6}$ Heck, A F, Neurology (Minneapolis), 1963, 13, 587.

7 Emanuel, R, Proceedings of the Royal Society of Medicine, 1972, 65, 939.

${ }^{8}$ Hewer, R L, British Heart fournal, 1969, 31, 5.

9 Olsen, E G J, Proceedings of the Royal Society of Medicine, 1972, 65, 941.

10 James, T N, and Fisch, C, American Heart fournal, 1963, 66, 164.

11 Boehm, T M, Dickerson, R B, and Glasser, S P, American fournal of the Medical Sciences, 1970, 260, 279.

12 Gach, J V, Adriange, M, and Franck, G, American fournal of Cardiology, $1971,27,436$

${ }^{13}$ Ruschhaupt, D G, Thilenius, O G, and Cassels, D E, American Heart fournal, 1972, 84, 95.

14 Van der Hauwaert, L G, and Dumoulin, M, British Heart fournal, 1976, 38, 1291.

15 Maron, B J, et al, Circulation, 1975, 52, 926.

${ }_{16}$ Larter, W E, et al, Circulation, 1976, 53, 19.

17 O'Brien, E T, Dajee, H, and Ward, O C, European fournal of Cardiology, 1977, 6, 15.

18 Pratt, R T C, The Genetics of Neurological Disorders, p 34. London, Oxford University Press, 1967.

19 Turner, E V, and Roberts, E, Fournal of Nervous and Mental Diseases $1938,87,74$.

20 Smith, E R, et al, Clinical Research, 1975, 23, $208 \mathrm{~A}$.

21 Smith, E R, et al, Annals of Internal Medicine, 1976, 85, 566

${ }^{22}$ Fischl, J, and Rabiah, S, Clinical Chemistry, 1964, 10, 281.

${ }^{23}$ Robinson, N, Curzon, G, and Theaker, P, fournal of Clinical Pathology, 1965, 18, 797.

\section{Treatment of arthritis associated with psoriasis}

The arthritis associated with psoriasis is, like rheumatoid arthritis, extremely variable in its pattern. Some patients remit completely; others have remissions and relapses; and fortunately only a few pursue an unrelenting course. Though there is no specific treatment for the disease, many drugs can alleviate symptoms, while others can apparently control the course of the illness.

The diagnosis of psoriatic arthropathy should be borne in mind for any patient presenting with polyarthritis, for joint manifestations may appear before the skin lesions. Recognising psoriatic arthritis is particularly important, because antimalarials (as used in the treatment of rheumatoid arthritis) may produce exfoliative dermatitis in patients with psoriasis. Direct questioning is essential: the patient may have had an attack of psoriasis years before and not volunteered this during routine history taking.

As with rheumatoid arthritis, educating patients about their disease is of supreme importance. Nearly all patients with arthritis are concerned not only about the present but about the future. The patient and his family should be told that some cases of psoriatic arthritis remit completely, that nearly every patient can be helped, and that it is rare for any patient to become completely crippled.

Treatment aims at maintaining the patient's confidence, easing his pain, and preserving or restoring function to the affected joints. For most mild cases simple analgesics such as aspirin or the non-steroidal anti-inflammatory drugs are helpful; it is extraordinary how variable is the response of individual patients to apparently similar pharmacological preparations. Side effects on the gut and the bone marrow may, however, present problems with phenylbutazone and indomethacin. A small dose of a corticosteroid- $2.5 \mathrm{mg}$ or $5 \mathrm{mg}$ of prednisolone at night-may be helpful if early morning stiffness is a problem. Local steroid injections may be useful provided there are no skin lesions or psoriasis near the affected joint, when the injection may lead to infection of the joint. Simple physical methods such as heat and ice may help and do not make the psoriasis worse. 
Should the disease be progressive and disabling, treatment should aim at controlling the arthritis rather than simply relieving symptoms. For reasons not yet understood drugs which may help in seropositive rheumatoid arthritis seem to be of no help to patients who carry the HLA B27 antigen. Neither gold ${ }^{2}$ nor penicillamine are of proved value in psoriatic arthritis, though some rheumatologists have reported that gold may be helpful ${ }^{3}$ and does not exacerbate the skin lesions. Allopurinol has been given on the basis that hyperuricaemia may accompany psoriasis. Long term, however, control of the disease is best achieved with antimitotic agents. Methotrexate, a folate antagonist, has been most widely used. For example, $\mathrm{Kersley}^{4}$ treated ten patients with psoriatic arthritis with oral methotrexate; skin lesions improved in eight of them and the joint symptoms improved in five. Ulceration of the mouth was common, but no blood dyscrasias occurred. Three patients with psoriatic arthritis all responded to intravenous methotrexate. ${ }^{5}$

Side effects are common with methotrexate, occurring in up to one-third of all patients. ${ }^{6}$ These may be serious and sometimes fatal. Liver damage is more common when the drug is given on a continuous low-dosage regimen than when given intermittently. ${ }^{7}$ Acute gout may complicate the intravenous use of methotrexate,$^{8}$ while gastrointestinal side effects include diarrhoea, haemorrhage, and perforation. Regular blood checks are mandatory for the early detection of bone-marrow depression.

Baum et al ${ }^{9}$ treated 13 patients with psoriasis and arthritis with 6-mercaptopurine in daily doses ranging from $20 \mathrm{mg}$ to $150 \mathrm{mg}$. Eleven of them showed improvement in three weeks or less, with minimal side effects. After treatment was stopped the remissions lasted for up to 10 months. Azathioprine has also been tried:10 the response of the arthritis was excellent or good in nine out of 10 patients, with concomitant but also fluctuating improvement of the skin lesions. In two patients treatment was stopped because of gut disturbances and in one because of mild thrombocytopenia.

In general, antimitotic agents should be reserved for refractory and fulminating cases which do not respond to conventional, less toxic drugs. We need controlled studies of drugs said to act long term, and though these are difficult to arrange they should not prove impossible.

1 Cornbleet, T, fournal of Investigative Dermatology, 1956, 26, 435.

2 Eastmond, C J, personal communication.

${ }^{3}$ Wright, V, Annals of the Rheumatic Diseases, 1961, 20, 123.

${ }^{4}$ Kersley, G D, Annals of the Rheumatic Diseases, 1968, 27, 64.

5 Auerbach, R, Archives of Dermatology, 1964, 90, 553.

${ }^{6}$ Black, R L, et al, fournal of the American Medical Association, 1964, 189, 743.

' Baker, H, British Fournal of Dermatology, 1970, 82, 65.

${ }^{8}$ Martin, J H, Gordon, M, and Wallace, R, Archives of Dermatology, 1967, 96, 431.

${ }^{9}$ Baum, J. et al, Arthritis and Rheumatism, 1973, 16, 139.

10 Feldges, D H, and Barnes, C G, Rheumatology and Rehabilitation, 1974, 13, 120.

11 Viglioglia, P A, et al, Dermatologica (Basel), 1970, 14, 203.

\section{Parsons's papilloedema, 70 years on}

Sir John Parsons (1868-1957) restricted the term papilloedema, which he introduced in 1908, to a swollen optic disc in association with raised intracranial pressure. Previously this condi- tion had been known as optic neuritis, the name given to it by von Graefe, who had observed changes in the optic discs in patients with intracranial tumours examined with the newly devised ophthalmoscope. ${ }^{1}$

Parsons's intention was to emphasise that this type of papilloedema was not an inflammatory condition. So what causes the swelling ? Electron microscopy has confirmed that in early papilloedema the swelling of the disc is due to excess of extra-axonal fluid. ${ }^{2}$ One view, still widely held, is that the oedema fluid is a transudate secondary to obstruction of the central retinal vein. The mechanism postulated is that raised intracranial pressure is transmitted to the intraorbital subarachnoid space surrounding the optic nerve, where it compresses the vein. Nevertheless, this view is untenable: obliteration of the perineural space does not prevent the development of papilloedema, nor does it occur after experimental occlusion of the vein in this way. ${ }^{34}$

Persistently raised intracranial pressure, however produced, eventually leads to generalised swelling of the brain. We discussed the effects of cerebral oedema-and its resolution with treatment with steroids, five years ago. ${ }^{5}$ Since then it has become possible to study the dynamics of the swollen brain by non-invasive techniques. Computerised axial tomography ${ }^{6}$ has shown that in so-called "benign intracranial hypertension" the ventricles are reduced to slits. The multidetector scintillation camera has shown areas of abnormality of the blood-brain barrier, remote from the site of the intracranial tumour, in areas where the brain is compressed against unyielding structures such as the falx and tentorium. ${ }^{7}$ The oedema, at first focal, eventually becomes generalised. In monkeys treated with triethyltin the brain swells because of the retention of sodium and water in the myelin of the central nervous system. ${ }^{8}$ The nerve fibres of the optic nerve are myelinated to within a few millimetres of the lamina cribrosa, so that the retrolaminar portion of the nerve is affected by this swelling. The classical papilloedema which the monkey subsequently develops (which is not due directly to triethyltin) is apparently caused by the swelling of the retrolaminar part of the optic nerves blocking the extra-axonal centripetal transport of tissue fluid. ${ }^{3}$

Another factor in the swelling of the papilloedematous disc is obstruction to the axoplasmic flow-similar to that found in a constricted region of a peripheral nerve. ${ }^{9}$ The axoplasm flows from the nucleus to the periphery of the neurone and any block leads to the accumulation of subcellular elements proximal to the constriction. Histopathologists have long recognised that among the delayed effects of papilloedema is swelling of the individual slender naked nerve axons. The varicosities enlarge, and when they become bulbous they appear to lose their connection with the axon, thus giving rise to "cytoid bodies."10 Since anoxia is a potent inhibitor of axoplasmic transport, the primary lesion may be ischaemia of the swollen retrolaminar segment of the optic nerve. ${ }^{11}$

In the evolution of papilloedema time must be taken into account. The earliest and therefore most fundamental change is an excess of extracellular fluid. ${ }^{2}$ In longstanding papilloedema the increase in the volume of the nerve head is largely due to axonal swelling. ${ }^{12}$ Various degrees of deficit of vision can usually be found at this stage. Swelling of the vessel-bearing part of the optic nerve impedes the flow in the central retinal vein, causing capillary hyperaemia, and on angiographic examination there is late extravascular fluorescence due to increased permeability. Nevertheless, in experiments in which angiography is done early in the development of papilloedema there may be no fluorescein leakage at the $\operatorname{disc}^{13}$; so clearly 